\title{
Precocious genotypes and homozygous tendency generated by self-pollination in walnut
}

Lingna Chen ${ }^{1,2+}$, Runquan Dong ${ }^{3 \dagger}$, Qingguo Ma', Yu Zhang ${ }^{3}$, Shizhong Xư ${ }^{4}$, Delu Ning ${ }^{3}$, Qin Chen $^{3}$ and Dong Pei ${ }^{1 *}$

\begin{abstract}
Background: Observations of precocious (early bearing) genotypes of walnut (Juglans regia L.) under natural conditions encouraged us to study the origin and genetic control of these fascinating traits.

Results: In this study, the self-fertility, progeny performance, and simple sequence repeat (SSR) locus variation of iron walnut (Juglans sigillata Dode), an ecotype of J. regia, were investigated. The average self-pollinated fruit set rate of J. sigillata cv. 'Dapao' (DP) was 7.0\% annually from 1979 to 1982. The average germination rate of self-pollinated seeds was $45.2 \%$ during the 4-year period. Most progeny had inbreeding depression. Nine representative self-pollinated progeny $\left(\mathrm{SP}_{1}-\mathrm{SP}_{9}\right)$, with special or typical traits of $\mathrm{DP}$, were selected. $\mathrm{SP}_{1}-\mathrm{SP}_{4}$ were precocious because they initiated flowers as early as 2 years after germination, compared to the 7-10-yr period that is typical of DP. SP 9 had not flowered since 1980. Twelve SSR markers were used to analyze the SP and DP. The genome of SP had a tendency toward high levels of homozygosity. The high levels of homozygosity reported in 18 additional precocious walnut genotypes complemented the results of this study.

Conclusions: These results provide evidence of precocious phenotypes and genomes with high levels of homozygosity that might be generated from self-pollinating walnut. This suggests that self-pollination might facilitate the generation of unique homozygous parents for subsequent use in walnut-breeding programs. The results also indicate that more attention should be focused on adequate management of precocious walnut to avoid early depression in the production of nuts.
\end{abstract}

Keywords: Juglans sigillata Dode, Juglans regia L., Self-pollination, Phenotype, Homozygosity, Juvenile period

\section{Background}

Precocity and prolificacy are important in fruit breeding programs, and an understanding of the knowledge is crucial in the assessment of clones that may be released as new cultivars [1-3]. In recent years, dwarf rootstocks and early-producing parents have been used to manage and shorten the juvenile period in many fruit trees, including apple, pear, citrus, olive, cherry, and walnut $[2,4,5]$. Negative correlations

\footnotetext{
* Correspondence: pei.dong@caf.ac.cn

${ }^{+}$Lingna Chen and Runquan Dong contributed equally to this work.

'State Key Laboratory of Tree Genetics and Breeding, Key Laboratory of Tree Breeding and Cultivation of the State Forestry and Grassland Administration, Research Institute of Forestry, Chinese Academy of Forestry, Beijing 100091, China

Full list of author information is available at the end of the article
}

between the length of the juvenile period and seedling vigor or tree size have been observed in different woody species $[2,4,6]$. These precocious and dwarf trees have attracted the attention of fruit growers throughout the world because of the potential for increased planting density, higher production and photosynthetic efficiency, effective spraying, and easy of harvesting [7-9].

Walnut (Juglans regia L.) is not considered to be a precocious tree [4]. It exhibits vigorous growth, but flowering is rarely initiated within $1-3 \mathrm{yr}$. of sowing. Early flowering has been preferentially selected in breeding programs to produce precocious cultivars. Rezaee et al. [7] reported that some precocious and dwarf walnut genotypes can be found among the

(c) The Author(s). 2018 Open Access This article is distributed under the terms of the Creative Commons Attribution 4.0 International License (http://creativecommons.org/licenses/by/4.0/), which permits unrestricted use, distribution, and 
seedlings of some J. regia genotypes from western Asia. In China, precocious genotypes have been selected mainly from the Aksu, Hotan and Kashgar regions of Xinjiang, which are situated in the Tarim Basin, in an area characterized by an arid climate, low precipitation, and strong evaporation $[10,11]$. However, little is known about the origins of the genotypes. Self-pollination and apomixis occur frequently due to floral variation and limited pollen production, based on the traits of the secondary flowers of precocious $J$. regia $[4,10,12]$. Many plants, including some heterodichogamous taxa, autonomously self-pollinate in natural populations, especially if pollen is limited $[13,14]$. Beineke [15] reported that self-pollination could occur when flowering times overlap in black walnut. Self-pollination typically results in broad phenotypic and physiological changes in plants [16]. In fruit crops such as pear (Pyrus pyrifolia) [17], almond (Prunus dulcis) [18], and some species of the Juglandaceae family, including Carya illinoensis, J. regia, J. nigra and J. mandshurica [15, 19], self-pollination causes inbreeding depression and generates dwarfed phenotypes. However, our knowledge of the genetic basis of self-pollination and the phenotype of self-pollinated progeny in the genus Juglans L., especially during the juvenile period is limited.

Iron walnut (Juglans sigillata Dode) is native to southwestern China and is an ecotype of J. regia [20,21]. It is a deciduous tree species known for its edible nuts and high-quality timber [22]. By the end of 2017, almost 3 million hectares of iron walnut were being harvested in Yunnan Province, and the production value was estimated to be almost 5 billion dollars. Iron walnut is also diploid, monoecious, heterodichogamous (individuals may be protandrous or protogynous), and wind-pollinated. It generally bears fruit approximately 7-10 yr. after sowing. The creation of precocious iron walnut genotype from seedling selection has not been reported in the literature. In this study, a self-pollination experiment was used to determine the self-pollinating capability and to observe the performance of self-pollinated progeny (SP), including the length of the juvenile period and botanical traits, from 'Dapao' (DP), an iron walnut cultivar important to Yunnan Province. Simple sequence repeat (SSR) markers were used to infer the genotypic composition of the self-pollinated plants and to understand their genetic traits. The objectives of this study were to provide evidence of new precocious walnut phenotypes, with high levels of homozygosity generated from self-pollination, and to provide guidance for the management of precocious walnut to avoid early depression in nut production.

\section{Methods}

\section{Plant material}

The experiments were conducted in Yangbi County of Dali, Yunnan, China $\left(25^{\circ} 39^{\prime} \mathrm{N}\right.$ and $100^{\circ} 01^{\prime} \mathrm{E}, 1850 \mathrm{~m}$
ASL). DP, a protandrous cultivar of iron walnut and the only genotype within an $800 \mathrm{~m}$ radius, was used in controlled pollination experiments from 1979 to 1982. At least 20 trees were selected for bagging each year. Harvested seeds were planted in the experimental walnut orchard of the Yangbi Walnut Research Institute, Yunnan Academy of Forestry, China (25 $39^{\prime} \mathrm{N}$ and $\left.99^{\circ} 59^{\prime} \mathrm{E}\right)$. The SP and the parent were grown on the same site. The parent DP and their SP were analyzed using SSR markers.

\section{Self-pollination of DP and phenotypes of their SP}

Female DP flowers were randomly selected and then isolated using a $40 \times 60 \mathrm{~cm}$ waterproof parchment bag to isolate random pollen grains from other genotypes. Pollen was collected from each genotype and stored in breathable phial at $2-4{ }^{\circ} \mathrm{C}$ [23]. All pollen was applied within $48 \mathrm{~h}$ to ensure viability. When the stigmas of the bagged female flowers were receptive, pollen was dusted onto them. Pollination was repeated the next day. At 25 days after pollination, bags were removed when the stigmas were completely dry. The number of fruits set was recorded at 8 weeks after anthesis and the self-pollinated fruit setting rate was recorded. The germination rate of the self-pollinated seeds was recorded after the stratification period, and the growth performance attributes of SP, such as the juvenile period, mass growth, and nut traits were continually observed. The un-germinated seeds were separated from the soil for measurement of the empty-nut ratio.

Phenotypic analyses, including the determination of bud, leaf and nut traits of DP and SP were conducted according to the International Union for the Protection of New Varieties of Plants [24] descriptors. During the harvest season, 10 nuts were collected from each tree except $\mathrm{SP}_{9}$ for the determination of nut traits (i.e., nut shape, nut size, single nut weight, shell thickness, and kernel percentage). Differences in single nut traits, shell thickness, and kernel percentage among SPs were compared by a one-way ANOVA using SAS (Version 9.2; SAS Institute Inc., Cary, NC, USA).

\section{SSR analysis of DP and SP}

In April 2016, at least six young leaves from the DP and SP plants were collected for extraction of genomic DNA, following the protocol described by Wang et al. [25]. Extracted DNA was quantified spectrophotometrically and diluted to $25 \mathrm{ng} / \mu \mathrm{l}$ before PCR amplification.

Genetic analysis of DP and SP plants was performed using 12 pairs of SSR primers (Table 1) selected for their polymorphisms. Nine primer pairs, prefixed "WJR", were from bacterial artificial chromosome end sequences of $J$. regia (downloaded from the National Center for 
Table 1 Profiles of the 12 pairs of primers used for the SSR analysis of DP and SP

\begin{tabular}{|c|c|c|c|c|}
\hline Code & Locus & Repeat motifs & Primer sequences $\left(5^{\prime}-3^{\prime}\right)$ & GenBank accession no. \\
\hline \multirow[t]{2}{*}{1} & WJR022 & $(\mathrm{AAG}) \mathrm{n}$ & F: ACGGGACCGGAGTTTACTIT & JM057F12 \\
\hline & & & R: CATGGCAGGAGAACTGGTTT & \\
\hline \multirow[t]{2}{*}{2} & WJR033 & $(T A) n$ & F: AGGGCTCCACTTGATCAGAA & JM056N06 \\
\hline & & & R: TCGGCAATCAACCAGATAAA & \\
\hline \multirow[t]{2}{*}{3} & WJR035 & $(\mathrm{TA}) \mathrm{n}$ & F: AGTGCATGCCTTGTCTCCTT & JM060C06 \\
\hline & & & R: TGCTCCTTGTCAGTCCACAG & \\
\hline \multirow[t]{2}{*}{4} & WJR061 & $(\mathrm{AT}) \mathrm{n}$ & F: CAAGACCACAGCACAGCATAA & JM008C04 \\
\hline & & & R: GGGAGTGCTGGAATCGAATA & \\
\hline \multirow[t]{2}{*}{5} & WJR087 & (TGTC)n & F: CCCCCAATATGTCTGCTTCT & JM012K14 \\
\hline & & & R: ACCATAGCTGGTTTGGCATC & \\
\hline \multirow[t]{2}{*}{6} & WJR100 & $(\mathrm{AT}) \mathrm{n}$ & F: CGACGATTCGGTGAAGAAAT & JM031J07 \\
\hline & & & R: GAAAACCCAGTTCTGTCGG & \\
\hline \multirow[t]{2}{*}{7} & WJR265 & $(\mathrm{AAT}) \mathrm{n}$ & F: TGGCTATTGCAAAATCAGGTC & JM021P05 \\
\hline & & & R: CAAAAGCATGTAGGTCGGGT & \\
\hline \multirow[t]{2}{*}{8} & WJR294 & $($ CAAAAC)n & F: TTACCTGCCAACACCAACA & JM017N12 \\
\hline & & & R: ACAAGGCGAAACAAACTGCT & \\
\hline \multirow[t]{2}{*}{9} & WJR309 & (T)n(TTG)n(TTC)n & F: TTGCAATAATGCGATGAACG & JM006J18 \\
\hline & & & R: TGACTTTGACCATGGCTTTG & \\
\hline \multirow[t]{2}{*}{10} & WGA070 & $(G A) n$ & F: TGTAATTGGGGAATGTTGCA & - \\
\hline & & & R:TGGGAGACACAATGATCGAA & \\
\hline \multirow[t]{2}{*}{11} & WGA079 & $(G A) n$ & F: CACTGTGGCACTGCTCATCT & - \\
\hline & & & R: TTCGAGCTCTGGACCACC & \\
\hline \multirow[t]{2}{*}{12} & WGA089 & $(T G) n,(G A) n$ & F:ACCCATCTITCACGTGTGTG & - \\
\hline & & & R:TGCCTAATTAGCAATTTCCA & \\
\hline
\end{tabular}

Biotechnology Information (NCBI) database: http:// www.ncbi.nlm.nih.gov/nucgss/ by querying juglans regia), and three pairs of primers, prefixed "WGA", were from the enriched $(\mathrm{GA} / \mathrm{CT}) \mathrm{n}$ microsatellite library of $J$. nigra [26]. The SSR reaction protocol was as described by Chen et al. [27]. The amplification reaction was performed in a volume of $20 \mu \mathrm{L}$ containing $1 \times$ polymerase chain reaction (PCR) buffer, $50 \mathrm{ng}$ of genomic DNA, $300 \mu \mathrm{M}$ dNTPs, $0.4 \mu \mathrm{M}$ of each primer, $3 \mathrm{mM}$ of $\mathrm{MgCl}_{2}$, and 1 unit of Taq DNA polymerase (TaKaRa Biotechnology, Dalian, China). PCR was performed on an ABI GeneAmp 9700 thermal cycler (Applied Biosystems, Foster City, CA, USA) with the following program: an initial 5-min incubation at $94{ }^{\circ} \mathrm{C}, 35$ cycles of $45 \mathrm{~s}$ at $94{ }^{\circ} \mathrm{C}, 45 \mathrm{~s}$ at the annealing temperature of $50-55^{\circ} \mathrm{C}, 45 \mathrm{~s}$ at $72{ }^{\circ} \mathrm{C}$, and a final incubation at $72{ }^{\circ} \mathrm{C}$ for 5 min. After amplification, $3 \mu \mathrm{L}$ of each sample were separated in a $6 \%$ denaturing polyacrylamide gel with $7 \mathrm{M}$ urea and $1 \times$ TBE (Tris-borate-EDTA) buffer, and visualized by silver staining. In all cases, PCR reactions were performed at least twice to ensure that the absence of bands was not due to a failed reaction.

The observed heterozygosity $\left(H_{\mathrm{O}}\right)$, expected heterozygosity $\left(H_{\mathrm{E}}\right)$, Nei's expected heterozygosity $(H)$, Shannon's information index $(I)$ of the 12 SSR loci and the allele frequency of DP and SP were calculated using POPGENE version 1.32 [28]. Selfing was assessed by estimating the fixation index $(F)$ and the homozygosis (Hom) for every SSR locus as $F=1-\left(H_{O} / H_{E}\right)$ and Hom $=1-H_{O}$, respectively, and the statistical significance for $F$ values was tested using 1000 permutations of alleles among individuals and Bonferroni correction (95\%, $p=0.05$ ), following the methods of Bressan et al. [29].

The difference in alleles among SP was evaluated by Student's $t$-test for independent samples using Excel 2010 (Microsoft Corp., Seattle, WA, USA).

\section{Results}

\section{Self-pollinating capability of iron walnut 'Dapao'}

DP had relatively stable self-pollinating capability, ranging from 5.4 to $9.3 \%$, with an average of $7.0 \%$, during the 4-yr period (Table 2). A total of 378 self-pollinated seeds were harvested. Among them, embryoless and empty seeds accounted for 31.2 and $23.5 \%$ of the harvested seeds, respectively. The remaining 171 (45.2\%) seeds germinated after stratifcation treatment. Most of 
Table 2 Self-pollinating capability of iron walnut 'Dapao'

\begin{tabular}{|c|c|c|c|c|c|c|}
\hline \multirow[t]{2}{*}{ Year } & \multirow{2}{*}{$\begin{array}{l}\text { Number of } \\
\text { bagged female } \\
\text { flowers }\end{array}$} & \multirow{2}{*}{$\begin{array}{l}\text { Number } \\
\text { of fruits set }\end{array}$} & \multirow{2}{*}{$\begin{array}{l}\text { Fruit setting } \\
\text { rate }(\%)\end{array}$} & \multicolumn{3}{|c|}{ Number of harvested seeds } \\
\hline & & & & $\begin{array}{l}\text { Number of germinated } \\
\text { seeds }\end{array}$ & $\begin{array}{l}\text { Number of embryoless } \\
\text { seeds }\end{array}$ & $\begin{array}{l}\text { Number of empty } \\
\text { seeds }\end{array}$ \\
\hline 1979 & 1722 & 93 & 5.4 & 39 & 31 & 23 \\
\hline 1980 & 1688 & 131 & 7.7 & 27 & 25 & 34 \\
\hline 1981 & 1786 & 96 & 5.4 & 37 & 27 & 17 \\
\hline 1982 & 1379 & 128 & 9.3 & 68 & 35 & 15 \\
\hline Total & 6575 & 448 & - & 171 & 118 & 89 \\
\hline Mean & - & - & 7.0 & - & - & - \\
\hline
\end{tabular}

the 171 seeds did not grow properly because of depression. Only 47 of the 171 plants survived and reached reproductive maturity.

\section{Phenotype variation of SP}

The most striking result of self-pollination observed in this study was SP depression, in terms of reduced growth and vitality. There were different levels of phenotypic changes. One trait of the juvenile period should be underlined. Three major categories of seedling were observed among the SP of DP. The length of the juvenile period was shortened from around the $7-10 \mathrm{yr}$. usually required by iron walnut to a 2-yr period for $\mathrm{SP}_{1}-\mathrm{SP}_{4}$. Also, $\mathrm{SP}_{9}$ never flowered. However, many SPs, represented by $\mathrm{SP}_{5}-\mathrm{SP}_{8}$, had similar lengths of juvenile period to their parents. The nine representative seedlings were retained to investigate the variation in botanic traits.

After more than $30 \mathrm{yr}$. of investigation, the botanic traits of SPs have been found to be basically stable. Growth traits of the nine normal SP plants are shown in Table 3. These plants had different leaflet and nut-shape features. $\mathrm{SP}_{1}-\mathrm{SP}_{4}$ had precocious traits and different stem colors and leaflet numbers compared to DP. $\mathrm{SP}_{5}-\mathrm{SP}_{8}$ exhibited a red rachis color, which was clearly different from the green color in DP and other SPs. $\mathrm{SP}_{6}$ had a circular mixed bud, unlike most SPs, which had triangular buds. $\mathrm{SP}_{4}$ and $\mathrm{SP}_{6}$ appeared to have different dichogamy types. The variation in nut shape was very significant, with three types of nut being apparent: Pao walnut (with $0.1-0.9 \mathrm{~mm}$ shell thickness in $\mathrm{SP}_{1}, \mathrm{SP}_{2}$, and $\mathrm{SP}_{6}$ ), Jiamian walnut (with $1.0-1.5 \mathrm{~mm}$ shell thickness in $\mathrm{SP}_{3}$, $\mathrm{SP}_{4}$, and $\mathrm{SP}_{5}$ ), and Tie walnut (with $1.6-2.0 \mathrm{~mm}$ and $>2.0$ $\mathrm{mm}$ shell thickness in $\mathrm{SP}_{7}$ and $\mathrm{SP}_{8}$, respectively). Shell thickness was significantly negatively related to the kernel percentage, with a very significant difference between $\mathrm{SP}_{7}$ and $\mathrm{SP}_{8}$ and the six other nut-bearing plants $(p<0.01)$. Among these plants, $\mathrm{SP}_{5}$ was most similar to DP in terms of phenotype.

\section{SSR analysis of DP and SP}

The 12 SSRs produced a total of 24 alleles among DP and SP. Among them, six SSR loci were heterozygous in the mother DP. There were no more than two SSR alleles per SP and DP. No new alleles appeared in SP, suggesting that the genome of SP was derived from DP. No SP displayed the same genotypes as the DP, indicating no apomictic progeny in this sample. The estimated average fixation index for the SP differed significantly from zero $(F=0.136, p<0.05)$. The expected heterozygosity $\left(H_{\mathrm{E}}\right)$ values for the 12 SSR loci ranged from 0.100 to 0.526 , with an average value of 0.356 . The Shannon's information index (I) ranged from 0.199 to 0.693 , with an average value of 0.502 (Table 4). The smallest number of alleles $(n=13)$ was observed in $\mathrm{SP}_{3}$, and the largest number $(n=18)$ was observed in the DP and $\mathrm{SP}_{5}$. The allele frequency ranged from 0.05 to 0.95 (Table 5). Homozygosis (Hom) per locus ranged from 0.300 to 0.900 . The percentages of homozygous loci in the SP genome were estimated to be $58 \%\left(\mathrm{SP}_{1}\right), 83 \%\left(\mathrm{SP}_{2}\right), 92 \%$ $\left(\mathrm{SP}_{3}\right), 83 \%\left(\mathrm{SP}_{4}\right), 50 \%\left(\mathrm{SP}_{5}\right), 58 \%\left(\mathrm{SP}_{6}\right), 58 \%\left(\mathrm{SP}_{7}\right), 75 \%$ $\left(\mathrm{SP}_{8}\right)$, and $83 \%\left(\mathrm{SP}_{9}\right)$, and that in the DP it was $50 \%$. SP had increased homozygosity in the genome. $\mathrm{SP}_{3}$ was the highest, while $\mathrm{SP}_{5}$ was the lowest and was similar to DP.

Student's $t$-test was used to evaluate allele differences in the 12 SSR loci between the short $\left(\mathrm{SP}_{1}-\mathrm{SP}_{4}\right)$ and long $\left(\mathrm{SP}_{5}-\mathrm{SP}_{8}\right)$ juvenile periods. A $P$ value of $0.080(t=-2.102, \mathrm{df}=6)$ was obtained, indicating a large difference between the two groups.

Twelve SSR primers were used to analyze genetic diversity, allele frequency, and the number of homozygous loci in 36 additional J. regia genotypes (Additional file 1), including 18 that initiated flowering within $1-3 \mathrm{yr}$. of sowing and 18 that initiated flowering more than $4 \mathrm{yr}$. after sowing. The expected heterozygosity $\left(H_{\mathrm{E}}\right)$ and Shannon's information index $(I)$ of the 12 SSR loci had average values of 0.623 and 1.129, respectively, indicating a high degree of polymorphism in the SSR loci (Additional file 2). The estimated average fixation index was also differed significantly from zero $(F=0.333, p<0.05)$. SSR genotyping revealed a significant difference in the level of homozygosity among groups $(t=6.204, \mathrm{df}=38, \quad P=0)$. The percentage of homozygous loci was larger in the precocious group $(64.90 \%)$ than in the long juvenile period group (47.85\%; Additional file 3). The percentages of 


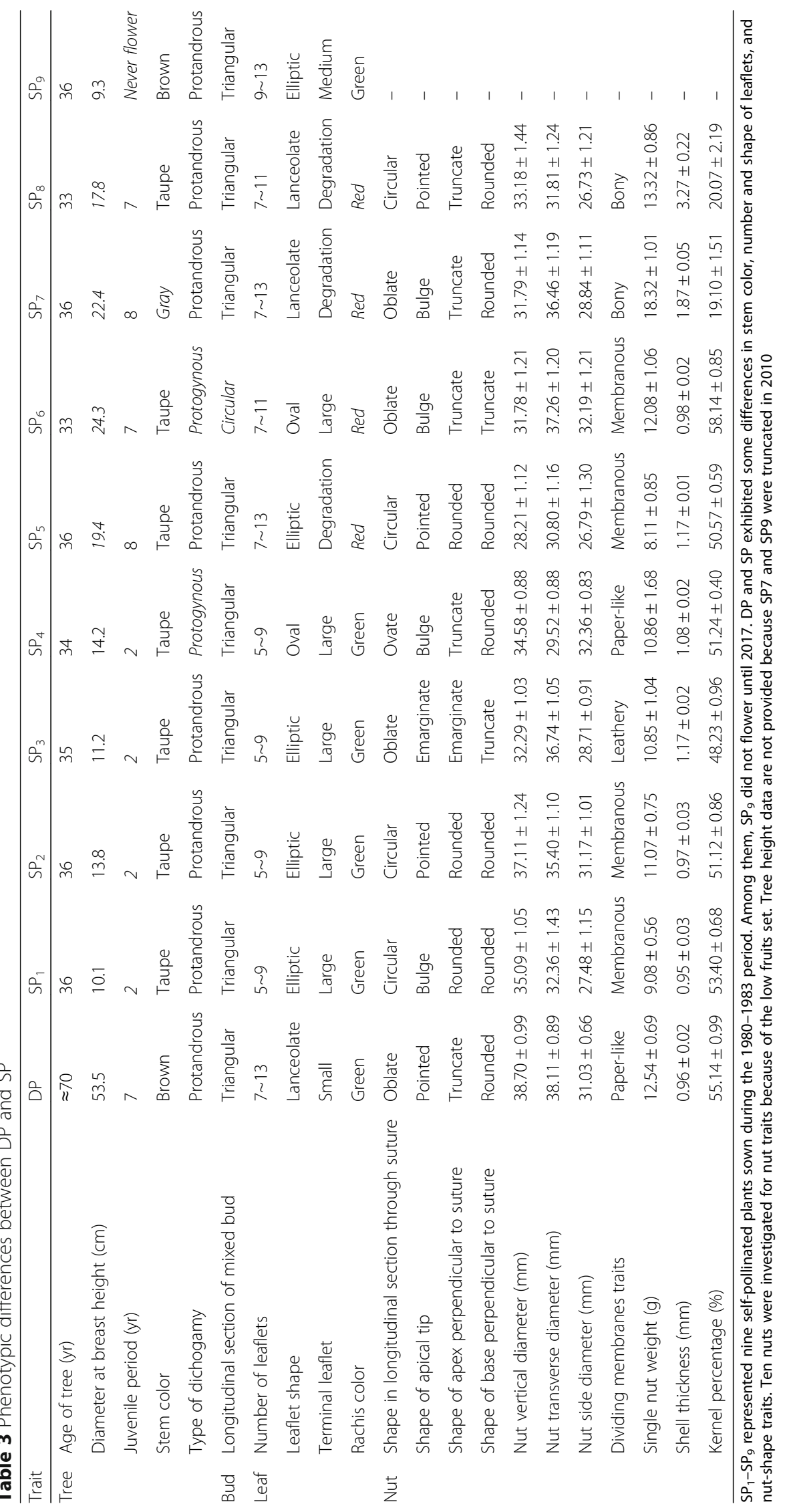


Table 4 Summary of genetic statistics for 12 SSR loci in DP and SP

\begin{tabular}{llllllll}
\hline Locus & Sample size & $H_{\mathrm{O}}$ & $H_{\mathrm{E}}$ & $H$ & l & $F$ & Hom \\
\hline WJR022 & 10 & 0.300 & 0.268 & 0.255 & 0.423 & -0.143 & 0.700 \\
WJR033 & 10 & 0.100 & 0.100 & 0.095 & 0.199 & 0.000 & 0.900 \\
WJR035 & 10 & 0.500 & 0.479 & 0.455 & 0.647 & -0.067 & 0.500 \\
WJR061 & 10 & 0.600 & 0.526 & 0.500 & 0.693 & -0.053 & 0.400 \\
WJR087 & 10 & 0.300 & 0.521 & 0.495 & 0.688 & 0.590 & 0.700 \\
WJR100 & 10 & 0.400 & 0.505 & 0.480 & 0.673 & 0.351 & 0.600 \\
WJR265 & 10 & 0.200 & 0.190 & 0.180 & 0.325 & -0.067 & 0.800 \\
WJR294 & 10 & 0.100 & 0.100 & 0.095 & 0.199 & 0.000 & 0.900 \\
WJR309 & 10 & 0.100 & 0.100 & 0.095 & 0.199 & 0.000 & 0.900 \\
WGA070 & 10 & 0.500 & 0.479 & 0.455 & 0.647 & 0.059 & 0.500 \\
WGA079 & 10 & 0.700 & 0.479 & 0.455 & 0.647 & -0.455 & 0.300 \\
WGA089 & 10 & 0.300 & 0.521 & 0.495 & 0.688 & 0.590 & 0.700 \\
Mean & 10 & 0.342 & 0.356 & 0.338 & 0.502 & 0.136 & 0.658 \\
St.dev. & & 0.202 & 0.187 & 0.177 & 0.216 & & \\
\hline
\end{tabular}

homozygous loci exceeded 70\% in four cultivars: 'Liaoning 2,'Lvbo,'ZZha 71', and 'Chandler'.

\section{Discussion}

\section{Self-pollination and self-compatibility of walnut}

Self-compatibility is common in heterodichogamous taxa, including Juglans and Acer [13, 30]. In the present study, an average self-pollinated fruit setting rate of $7.0 \%$ was recorded for 'Dapao' during the 4-yr experiment, suggesting that the species might be self-compatible, like other species of Juglans $[13,31]$ or there is individual variation for self-incompatibility and some trees might set seed from self-fertilization, where other not. Whatever the case, the selfing capacity has been applied in breeding programs for self-pollinated fruit crops, such as cherry [32]. Conveniently, self-pollination can occur in natural populations of walnuts, especially if pollen dispersal distance is limited [14, 19, 33]. In southern Xinjiang regions, such as Kashgar and Hotan, frequent sandstorms and severe droughts might seriously interfere with the cross-pollination of walnut in April and May, which corresponds to the blooming stage. As a result, the proportion of selfed or inbred progeny from climate-stress trees in the seed gene pool might be dramatically increase in the region, which was also noted

Table 5 Allele frequency of DP and SP

\begin{tabular}{cllllll}
\hline AlleleVLocus & WJR022 & WJR033 & WJR035 & WJR061 & WJR087 & WJR100 \\
Allele A & 0.15 & 0.95 & 0.35 & 0.50 & 0.55 & 0.40 \\
Allele B & 0.85 & 0.05 & 0.65 & 0.50 & 0.45 & 0.60 \\
AlleleVLocus & WJR265 & WJR294 & WJR309 & WGA070 & WGA079 & WGA089 \\
Allele A & 0.90 & 0.95 & 0.05 & 0.35 & 0.35 & 0.45 \\
Allele B & 0.10 & 0.05 & 0.95 & 0.65 & 0.65 & 0.55 \\
\hline
\end{tabular}

in a study of seed productive responses to drought stress in Pinus sylvestris [34]. Self-pollination and apomixis occur frequently due to floral variation and limited pollen among the secondary flowers of the precocious $J$. regia $[4,10,12]$, although the study did not provide evidence of the generation of the precocious genotype from apomixis. The special climate of southern Xinjiang might enable the formation of precocious walnuts [10]. The self-pollinating capacity could compensate for the negative effects of limited pollen or provide actual reproductive assurance in this ecological contexts [35, 36].

However, in other woody plants, such as Ceiba pentandra and Davidia involucrata, self-pollination or inbreeding can result in the expression of lethal or deleterious alleles that cause the production of aborted and un-germinated seeds [37, 38]. In this study, the $45.2 \%$ germination rate of self-pollinated seeds was lower than that of black walnut (72.7\%), as reported by Beineke [15]. Survival of only an estimated $25 \%$ of the self-pollinated plants was due to poor fitness, which was attributed to inbreeding depression. The self-pollinating capacity remains vital to the evolution of walnut; self-pollination can be tolerated by some plant species because many mildly deleterious alleles that could contribute to inbreeding depression were previously purged through natural selection [16, 39, 40]. Bressan et al. [29] reported that not all individuals produced from selfing were eliminated by inbreeding depression after germination (post-zygotic control). This is also an important trait in autogamous species [41]. The low vigor and high homozygous genotypes caused by self-pollination could provide the genetic material for tree size control and cross breeding $[8,41]$.

\section{Phenotypes and genotypes of SP}

Phenotypic variation in SP was observed in this study. More specifically, several precocious genotypes, flowering after $2 \mathrm{yr}$., were induced by self-pollination. The growth of those plants was substantially reduced compared to plants that had a juvenile period similar to their parent. The shell thickness of their nuts also varied markedly from $0.9-1.0$ to $3.0-3.5 \mathrm{~mm}$. There are few literatures reporting the effects of self-pollination on the juvenile period and fruit traits of plants. Lahav et al. [42] concluded that there were no differences in the length of the juvenile period among Persea americana progeny that originated from self-pollination and outcrossing. However, self-pollinated plants with low vigor and growth have been observed in some perennial plants, including J. regia and J. nigra [15]. A significant relationship between growth vigor and precocity levels has been reported in fruit trees, including pecan, olive, citrus, and walnut $[2,4,6,43]$. The slow growth and short stature (4.5 to $5.5 \mathrm{~m})$ of the four SP were 
consistent with previous reports. The differences in self-pollination effects among phenotypes and growth stages may reflect differences in either the number or type of deleterious mutations or the loss of the heterozygote advantage [38, 39].

SSRs are ideal markers for characterizing relationships and analysis of variation between walnut individuals [44-46]. The genotype analysis based on SSR marker data revealed an increased homozygosity in SP compared with DP. The degree and type of homozygosity differed among the SP genomes, which might reflect differences in the accumulation of mutations and adaptability [40, 41]. An earlier study on Persea americana investigated whether self-pollinations could be deployed to shorten the juvenile period, and indicated no significant effects of the homozygosity level on the length of the juvenile period [41]. Results from a study on Cocos nucifera suggested a relationship between a short juvenile period and higher homozygosity [47]. In our supplementary study, SSR genotyping of several precocious walnut cultivars, including 'Liaoning 2', 'Lvbo', and 'Zha 71', which are cultivated widely in China, resulted in a high proportion of homozygous loci (>70\% of SSR loci analyzed; Additional file 3). Although we cannot rule out the possibility that the differences in the juvenile period among SPs in our experiment were caused by increased homozygosity, our results were more supportive of a short juvenile period in connection with higher homozygosity in the genome.

For SPs, the estimated average fixation index was 0.136 , which was significantly below the minimum expected value of 0.5 for selfing [29]. This might be related to the fact that the present analysis was based in germinated seeds, probably subject of early inbreeding depression, killing some inbreed genotype combinations and natural selection favouring some inbreed genotypes, although the small family sample size very probably have also affected the inheritance of maternal alleles. For heterozygous loci in the mother, the expected $H_{\mathrm{E}}$ within families would be more close to 0.5. However, more important, in general homozygous genotypes were favored $(>0.5)$, resulting in higher homozygous than heterozygous genotypes, with exception of loci WJR061 and WGA079, there the opposite was detected. Therefore, the selection favouring homozygous genotypes might be the main cause of the differences between the observed (0.136) than expected F values (0.5). The similar result is also observed among natural walnut population in Iran, and there is inbreeding among the sampled populations [44, 46, 48].

In summary, the juvenile period was influenced by the combined effects of many recessive variants dispersed across the genome. This might also be true for other tree traits, and represents a new means of understanding the influence of genetic variation on tree performance.

\section{Implications of self-pollination for walnut breeding}

In the present study, iron walnut self-pollination contributed to a shortened juvenile phase in SP. This is the first evidence that self-pollination produces precocious genotypes in iron walnut. Thus, it seems that self-pollination can benefit traditional plant breeding programs [39, 49]. However, the precocity due to increased homozygosity and fitness reduction caused by self-pollination suggest that this is a depressed trait. Precocity has been widely used in breeding programs in China, and seems to be ideal for use in northern China [11, 12]. These facts also suggest that more attention should be focused on strengthening management of water and fertilizers, controlling a reasonable number of fruit-bearing flowers and selecting rootstock with strong growth for precocious walnut to avoid early depression.

On the other hand, self-pollination can cause increased homozygosity of individuals, which can be tested for their usefulness as new cultivars and/or enhance the fitness of their offspring when intercrossed with other germplasms [40]. Thus, plants possessing a short juvenile period and partially homozygous genome induced by self-pollination would create unique homozygous parents and be an excellent germplasm resource for iron walnut breeding.

In summary, these results provide evidence for the origin and heritability of precocious walnut and signs for recognition and utilization of self-pollination in walnuts. Also, the results suggest a new method of generating genetic variation in walnut breeding.

\section{Additional files}

\section{Additional file 1: Detailed information of 18 walnut genotypes with short juvenile period and 18 walnut genotypes with long juvenile period. (DOC $42 \mathrm{~kb}$ ) \\ Additional file 2: Summary of genetic statistics for 12 SSR loci in the 36 genotypes analyzed. (DOC $44 \mathrm{~kb}$ )}

Additional file 3: Percentage of homozygous loci in the 36 genotypes analyzed. (DOC $38 \mathrm{~kb}$ )

\section{Acknowledgments}

We thank the anonymous reviewers for constructive suggestions that helped to improve this paper.

\section{Funding}

This project was supported by the National Natural Science Foundation of China (grant No. 31672126).

Availability of data and materials

All data generated or analyzed during this study are included in this published article (and its additional files). 


\section{Authors' contributions}

LC performed genotyping for plant materials, analyzed all data, and drafted the manuscript; RD carried out the self-pollinating experiment and the early management of self-pollinated seeds; QM contributed to the experiment design and data analysis; YZ and DN performed phenotypic observation; SX and QC were mainly responsible for the management of the seedlings; DP conceived the study, contributed to its design, and critically revised the manuscript. All authors read and approved the final manuscript.

\section{Ethics approval and consent to participate}

Not applicable.

\section{Consent for publication}

Not applicable.

\section{Competing interests}

The authors declare that they have no competing interests.

\section{Publisher's Note}

Springer Nature remains neutral with regard to jurisdictional claims in published maps and institutional affiliations.

\section{Author details}

${ }^{1}$ State Key Laboratory of Tree Genetics and Breeding, Key Laboratory of Tree Breeding and Cultivation of the State Forestry and Grassland Administration, Research Institute of Forestry, Chinese Academy of Forestry, Beijing 100091, China. ${ }^{2}$ Research Institute of Resources Insects, Chinese Academy of Forestry, Kunming 650233, Yunnan, China. ${ }^{3}$ Yunnan Academy of Forestry, Kunming 650204, Yunnan, China. ${ }^{4}$ Dali Forest Resource Management Station, Dali 671000, Yunnan, China.

\section{Received: 12 June 2018 Accepted: 21 November 2018}

\section{Published online: 04 December 2018}

\section{References}

1. Karelia V, Jesús A, Vives MC, Pablo A, Pina JA, Pedro M, Luis N, Guerri J. Precocious flowering of juvenile citrus induced by a viral vector based on Citrus leaf blotch virus: a new tool for genetics and breeding. Plant Biotechnol J. 2016;14:1976-85.

2. Rallo P, Jiménez R, Ordovás J, Suárez MP. Possible early selection of short juvenile period olive plants based on seedling traits. Aust J Agric Res. 2008; 59:933-40.

3. Moral J, Díez CM, León L, De la Rosa R, Santos-Antunes F, Barranco D, Rallo L. Female genitor effect on the juvenile period of olive seedlings. Sci Hortic. 2013:156:99-105

4. Vahdati K, Mohseniazar M. Early bearing genotypes of walnut: a suitable material for breeding and high density orchards. Acta Hortic. 2016:1139:101-6.

5. Continella A, Pannitteri C, Malfa SL, Legua P, Distefano G, Nicolosi E, Gentile A. Influence of different rootstocks on yield precocity and fruit quality of 'Tarocco Scirè' pigmented sweet orange. Sci Hortic. 2018;230:62-7.

6. Thompson TE, Grauke LJ. Pecan tree growth and precocity. J Am Soc Hortic Sci. 2003:128:63-6.

7. Rezaee $R$, Vahdati $K$, Valizadeh M. Variability of seedling vigour in persian walnut as influenced by the vigour and bearing habit of the mother tree. J Hortic Sci Biotechnol. 2009;84:228-32.

8. Vahdati K, Mirmasoumi M, Rezaee R. Rooting and multiplication ability of Persian walnut as influenced by motherstock vigor and precocity. Acta Hortic. 2009:839:223-8.

9. Foster TM, Mcatee PA, Waite CN, Boldingh HL, Mcghie TK. Apple dwarfing rootstocks exhibit an imbalance in carbohydrate allocation and reduced cell growth and metabolism. Hortic Res. 2017:4:17009.

10. Li M, Liu Y, Zhao Y, Sun M, Zhang X, Yang K, Guo Q. Studies on floral variation in walnut (Juglans regia L.). Acta Hortic Sinica. 2009;36:21-6.

11. Wang GA, Zhang Q, Huang MM, Yakup A. The breeding of six Xinjiang dwarf walnut cultivars. Acta Hortic. 2013;1050:151-9.

12. Bernard A, Lheureux F, Dirlewanger $E$. Walnut: past and future of genetic improvement. Tree Genet Genomes. 2018;14:1.

13. Kimura MK, Goto S, Suyama Y, Matsui M, Woeste K, Seiwa K. Morph-specific mating patterns in a low-density population of a heterodichogamous tree, Juglans ailantifolia. Plant Ecol. 2012;213:1477-87.
14. Peng DL, Ou XK, Xu B, Zhang ZQ, Niu Y, Li ZM, Sun H. Plant sexual systems correlated with morphological traits: reflecting reproductive strategies of alpine plants. J Syst Evol. 2014;52:368-77.

15. Beineke WF. The effects of inbreeding in black walnut. In: Proceedings of the Indiana Academy of Science, vol. 97; 1987. p. 105-8.

16. Zhang M, Zhou L, Bawa R, Suren H, Holliday JA. Recombination rate variation, hitchhiking, and demographic history shape deleterious load in poplar. Mol Biol Evol. 2016;33:msw169.

17. Sato A, Sawamura Y, Takada N, Hirabayashi T. Relationship between inbreeding coefficients and plant height of 1-year-old seedlings in crosses among Japanese pear (Pyrus pyrifolia Nakai) cultivars/selections. Sci Hortic. 2008;117:85-8.

18. Martínez-García PJ, Dicenta F, Ortega E. Anomalous embryo sac development and fruit abortion caused by inbreeding depression in almond (Prunus dulcis). Sci Hortic. 2011:133:23-30.

19. Bai WN, Zeng YF, Zhang DY. Mating patterns and pollen dispersal in a heterodichogamous tree, Juglans mandshurica (Juglandaceae). New Phytol. 2007;176:699-707.

20. Wang H, Pan G, Ma QG, Zhang JP, Pei D. The genetic diversity and introgression of Juglans regia and Juglans sigillata in Tibet as revealed by SSR markers. Tree Genet Genomes. 2015;11:1.

21. Zhao P, Zhou HJ, Potter D, Hu YH, Feng XJ, Dang M, Feng L, Zulfiqar S, Liu WZ, Zhao GZ, Woeste K. Population genetics, phylogenomics and hybrid speciation of Juglans in China determined from whole chloroplast genomes, transcriptomes, and genotyping-by-sequencing (GBS). Mol Phylogenet Evol. 2018; https://doi.org/10.1016/j.ympev.2018.04.014.

22. Pei D, Lu XZ. Walnut germplasm resources in China. Beijing: China Forestry Publishing House; 2011.

23. Liu WS. Preliminary report on experiments on germination of walnut pollen. Sci Silvae Sin. 1963:8:272-4.

24. TG/125/6. Guidelines for the conduct of tests for distinctness, uniformity and stability of Juglans regia $\mathrm{L}$. (Walnut). International Union For The Protection Of New Varieties Of Plants (UPOV); 1999.

25. Wang H, Pei D, Gu RS, Wang BQ. Genetic diversity and structure of walnut populations in central and southwestern China revealed by microsatellite markers. J Am Soc Hortic Sci. 2008:133:197-203.

26. Woeste K, Burns R, Rhodes O, Michler C. Thirty polymorphic nuclear microsatellite loci from black walnut. J Hered. 2002;93:58-60.

27. Chen $L N$, Ma QG, Chen YK, Wang BQ, Pei D. Identification of major walnut cultivars grown in China based on nut phenotypes and SSR markers. Sci Hortic. 2014;168:240-8.

28. Yeh FC, Yang R, Boyle T. POPGENE Version 1.32 Microsoft Windows-based freeware for populations genetic analysis. Edmonton: University of Alberta; 1999.

29. Bressan EA, Sebbenn AM, Ferreira RR, Lee TSG, Fiqueira A. Jatropha curcas L. (Euphorbiaceae) exhibits a mixed mating system, high correlated mating and apomixis. Tree Genet Genomes. 2013;9:1089-97.

30. Kikuchi S, Shibata M, Tanaka H. Effects of forest fragmentation on the mating system of a cool-temperate heterodichogamous tree Acer mono. Glob Ecol Conserv. 2015:3:789-801.

31. Victory ER, Glaubitz JC, Rhodes JOE, Woeste KE. Genetic homogeneity in Juglans nigra (Juglandaceae) at nuclear microsatellites. Am J Bot. 2006:93:118-26.

32. Schuster M, Grafe C, Wolfram B, Schmidt H. Cultivars resulting from cherry breeding in Germany. Erwerbs-obstbau. 2014:56:67-72.

33. Mohsenipoor S, Vahdati K, Amiri R, Mozaffari M. Study of the genetic structure and gene flow in Persian walnut (Juglans regia L.) using SSR markers. Acta Hortic. 2010;861:133-42.

34. Kuznetsova NF. Development of specific and nonspecific reponses to stress in Pinus sylvestris L. at population level in a gradient of drought years. Russ $J$ Ecol. 2015;46:405-10.

35. Delmas CE, Cheptou PO, Escaravage N, Pornon A. High lifetime inbreeding depression counteracts the reproductive assurance benefit of selfing in a mass-flowering shrub. BMC Evol Biol. 2014;14:243.

36. Pellegrino $G$, Bellusci F, Palermo AM. Effects of population structure on pollen flow, clonality rates and reproductive success in fragmented Serapias lingua populations. BMC Plant Biol. 2015;15:1-10.

37. Lobo JA, Jiménez D, Solíshernández W, Fuchs EJ. Lack of early inbreeding depression and distribution of selfing rates in the neotropical emergent tree Ceiba pentandra: assessment from several reproductive events. Am J Bot. 2015;102:983-91.

38. Meng L, Dong X, Peng J, Wen X, Rui R, Liu J, Gao F, Liu Z. De novo transcriptome sequencing and gene expression analysis reveal potential 
mechanisms of seed abortion in dove tree (Davidia involucrate Baill.). BMC Plant Biol. 2016;16:82.

39. Charlesworth $\mathrm{D}$, Willis JH. The genetics of inbreeding depression. Nat Rev Genet. 2009:10:783-96.

40. González AM, De Ron AM, Lores M, Santalla M. Effect of the inbreeding depression in progeny fitness of runner bean (Phaseolus coccineus L.) and it is implications for breeding. Euphytica. 2014;200:413-28.

41. Debnath S, Guha S. Breeding methods for quality improvement in horticultural crops. In: Sharangi A, Datta S, editors. Value addition of horticultural crops: recent trends and future directions. New Delhi: Springer; 2015.

42. Lahav E, Lavi U. Avocado genetics and breeding. In: Jain SM, Priyadarshan PM, editors. Breeding plantation tree crops: tropical species. New York: Springer; 2009.

43. Mitani N, Matsumoto R, Yoshioka T, Kuniga T. Citrus hybrid seedlings reduce initial time to flower when grafted onto shiikuwasha rootstock. Sci Hortic. 2008;116:452-5.

44. Karimi R, Ershadi A, Vahdati K, Woeste K. Molecular characterization of Persian walnut populations in Iran with microsatellite markers. Hortscience. 2010;45:1403-6.

45. Francesca Pop I, Cristina Vicol A, Botu M, Andrei Raica P, Vahdati K, Pamfil D. Relationships of walnut cultivars in a germplasm collection: comparative analysis of phenotypic and molecular data. Sci Hortic. 2013;153:124-35.

46. Vahdati K, Mohseni Pourtaklu S, Karimi R, Barzehkar R, Amiri R, Mozaffari M, Woeste K. Genetic diversity and gene flow of some Persian walnut populations in southeast of Iran revealed by SSR markers. Plant Syst Evol. 2015:301:691-9.

47. Batugal P, Bourdeix R. Conventional coconut breeding. In: Batugal PA, Ramanatha Rao V, Oliver J, editors. Coconut genetic resources. Rome: IPGRI; 2005.

48. Karimi R, Ershadi A, Vahdati K, Ehtesham Nia A, Sharifani M, Rasouli M, Ebrahimi A. Morphological and molecular evaluation of Persian walnut populations in northern and western regions of Iran. J Nuts. 2014;5:21-31.

49. Ramírez N, Nassar JM. Breeding systems in angiosperms: novel inferences from a new analytical approach. Plant Syst Evol. 2017;303:119.

Ready to submit your research? Choose BMC and benefit from:

- fast, convenient online submission

- thorough peer review by experienced researchers in your field

- rapid publication on acceptance

- support for research data, including large and complex data types

- gold Open Access which fosters wider collaboration and increased citations

- maximum visibility for your research: over $100 \mathrm{M}$ website views per year

At $\mathrm{BMC}$, research is always in progress.

Learn more biomedcentral.com/submissions 